\title{
Crack initiation at high loading rates applying the four-point bending split Hopkinson pressure bar technique
}

\author{
Sebastian Henschel ${ }^{\mathrm{a}}$ and Lutz Krüger \\ Institute of Materials Engineering, TU Bergakademie Freiberg, Gustav-Zeuner-Str. 5, 09599 Freiberg, Germany
}

\begin{abstract}
Dynamic crack initiation with crack-tip loading rates of $\dot{K} \approx 2 \cdot 10^{6} \mathrm{MPa} \sqrt{\mathrm{ms}^{-1}}$ in a high strength G42CrMoS4 steel was investigated. To this end, a previously developed split Hopkinson pressure bar with four-point bending was utilised. Vnotched and pre-cracked Charpy specimens were tested. The detection of dynamic crack initiation was performed by analysing the dynamic force equilibrium between the incident and the transmission bar. Additionally, the signal of a near-field strain gauge and high-speed photography were used to determine the instant of crack initiation. To account for vibrations of the sample, a dynamic analysis of the stress intensity factor was performed. The dynamic and static analyses of the tests produced nearly the same results when a force equilibrium was achieved. Fracture-surface analysis revealed that elongated MnS inclusions strongly affected both the dynamic crack initiation and growth. Blunting of the precrack did not take place when a group of MnS inclusions was located directly at the precrack tip. Due to the direction of the elongated MnS inclusions perpendicular to the direction of crack growth, the crack could be deflected. The comparison with a $42 \mathrm{CrMo} 4$ steel without elongated $\mathrm{MnS}$ inclusions revealed the detrimental effect in terms of resistance to crack initiation. Taking the loading-rate dependency into consideration, it was shown that there was no pronounced embrittlement due to the high loading rates.
\end{abstract}

\section{Introduction}

For the investigation of dynamic fracture toughness properties at high loading rates, the split Hopkinson pressure bar principle is used, e.g. [1-5]. It enables the determination of forces and displacements on both the loading and support faces of the specimen $[4,5]$.

Materials which exhibit linear-elastic behaviour under high loading rates are subject of intensive research [2,4-6]. However, investigation dealing with elasticplastic behaviour are rare [7].

Dynamic crack initiation can be detected by a strain gauge in the near-field of the crack tip [8]. Furthermore, the strain gauge can be utilised to determine the stress intensity factor at the crack tip assuming a static calibration of the strain gauge [9].

In a study of a C45 low carbon steel, Klepaczko [10] observes a minimum of the plane strain fracture toughness at $10^{4} \mathrm{MPa} \sqrt{\mathrm{ms}^{-1}}$. Furthermore, Klepaczko [11] points out that low strain hardening favours the formation of a minimum fracture toughness at high loading rates.

The aim of the present study is the determination of crack initiation at high rates of the stress intensity factor of $\dot{K} \approx 2 \cdot 10^{6} \mathrm{MPa} \sqrt{\mathrm{ms}^{-1}}$ for a high-strength, tough and ductile G42CrMoS4 steel. To this end, a previously developed split Hopkinson pressure bar with four-point bending was utilised. V-notched and pre-cracked Charpy specimens were tested. Dynamic crack initiation was detected by a near-field strain gauge and by analysis of the force equilibrium. Furthermore, high-speed photography was utilised to evaluate the specimen loading.

${ }^{a}$ Corresponding author: sebastian.henschel@iwt.tu-freiberg.de

\section{Materials and methods}

\subsection{Investigated steel}

In this study, the resistance against crack initiation of the quenched and tempered cast steel G42CrMoS4 (1.7231) was evaluated. Heat treatment was performed by austenitising at $840{ }^{\circ} \mathrm{C}$ in a vacuum, followed by quenching in a stream of $\mathrm{He}$. The samples were tempered at $560{ }^{\circ} \mathrm{C}$ in a $\mathrm{N}_{2}$ atmosphere. After heat treatment, the microstructure of this steel consisted of tempered martensite. For comparison, a hot-rolled $42 \mathrm{CrMo} 4$ (1.7225) steel in the quenched and tempered state was tested.

The heat-treated samples were precracked up to $a_{0} / W \approx 0.5$ by utilisation of the crack length-dependent resonant frequency response. The precracking was started with a crack tip loading of $\Delta K=18 \mathrm{MPa} \sqrt{\mathrm{m}}$ at a stress ratio of $R=0.1$. The size of the plastic zone in front of the crack tip was minimised by load reduction during the precracking procedure.

\subsection{Apparatus}

The set-up of the split Hopkinson pressure bar is shown in Fig. 1. Striker, incident bar, transmission bar and momentum trap were made of a high strength AA7075 aluminium wrought alloy. The incident bar and the transmission bar had the same cross sectional area $\left(707 \mathrm{~mm}^{2}\right)$ due to the tubular shape of the transmission bar. Four-point bending of the specimen was achieved by two loading pins in the incident bar as well as in the transmission bar.

This is an Open Access article distributed under the terms of the Creative Commons Attribution License 4.0, which permits unrestricted use, distribution, and reproduction in any medium, provided the original work is properly cited. 


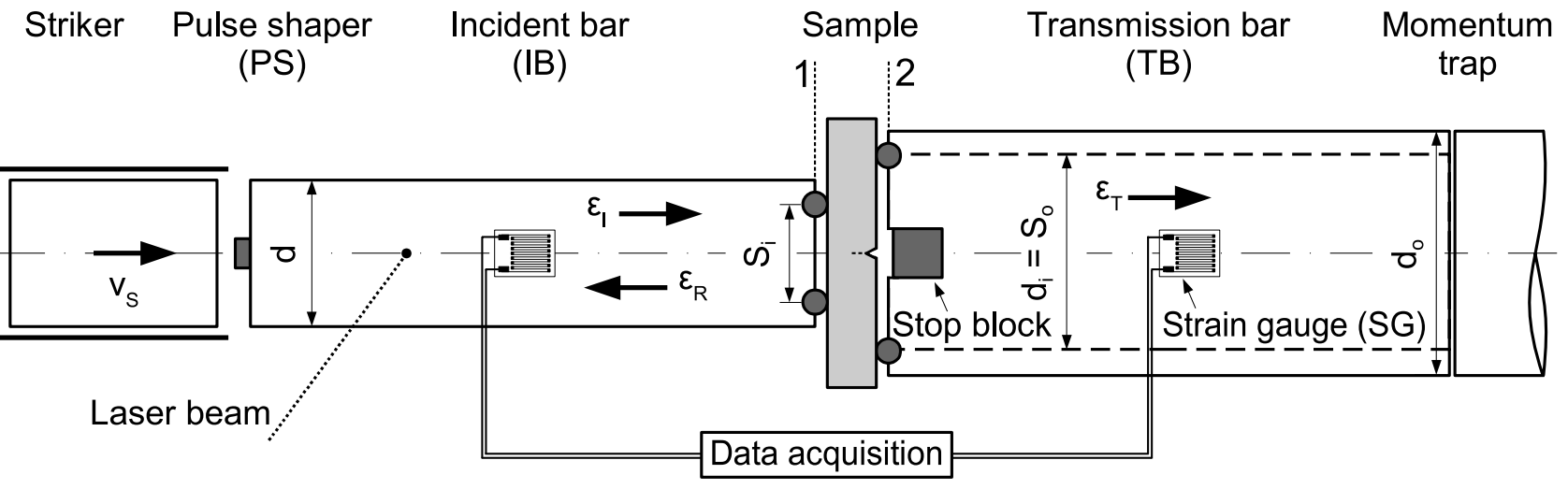

Figure 1. Schematic drawing of the four-point bending split Hopkinson pressure bar. Inner span $S_{\mathrm{i}}=20 \mathrm{~mm}$, outer span $S_{\mathrm{o}}=40 \mathrm{~mm}$.

The incident pulse was generated by the impact of the striker at the incident bar. Pulse shaping was applied to obtain a smooth incident pulse [12]. Due to the impedance mismatch at interface 1 (Fig. 1), the incident pulse $\left(\varepsilon_{\mathrm{I}}\right)$ was partially reflected $\left(\varepsilon_{\mathrm{R}}\right)$ and partially transmitted in the transmission bar $\left(\varepsilon_{\mathrm{T}}\right)$. Strain gauges $(\mathrm{SG})$ at the mid-length of the bars were used to measure strain introduced by these pulses. Additionally, a laser system (Polytec OFV525) was utilised to measure the surface velocity of the incident bar. The strain of the stress pulse was calculated by the measured surface velocity $v_{\mathrm{B}}$ and the sonic speed of the bar $c_{\mathrm{B}}[13]$ :

$$
\varepsilon=v_{\mathrm{B}} / c_{\mathrm{B}}
$$

The small gauge length of the strain gauges $(3.5 \mathrm{~mm})$ in combination with a $1 \mathrm{MHz}$ bandwidth amplifier (Tektronix AM502) and a high sampling frequency of $20 \mathrm{MHz}$ enabled the measurement of small rise times.

Forces $F_{1}, F_{2}$ and displacements $z_{1}, z_{2}$ at the interfaces 1 and 2 were determined by

$$
\begin{aligned}
& F_{1}(t)=F_{\mathrm{I}}(t)+F_{\mathrm{R}}(t)=\frac{\pi}{4} d^{2} E_{\mathrm{B}}\left(\varepsilon_{\mathrm{I}}(t)+\varepsilon_{\mathrm{R}}(t)\right) \\
& F_{2}(t)=F_{\mathrm{T}}(t)=\frac{\pi}{4}\left(d_{\mathrm{O}}^{2}-d_{\mathrm{i}}^{2}\right) E_{\mathrm{B}} \varepsilon_{\mathrm{T}}(t) \\
& z_{1}(t)=c_{\mathrm{B}} \int_{0}^{t}\left(\varepsilon_{\mathrm{I}}\left(t^{\prime}\right)+\varepsilon_{\mathrm{R}}\left(t^{\prime}\right)\right) \mathrm{d} t^{\prime} \\
& z_{2}(t)=c_{\mathrm{B}} \int_{0}^{t} \varepsilon_{\mathrm{T}}\left(t^{\prime}\right) \mathrm{d} t^{\prime} .
\end{aligned}
$$

The modulus of elasticity of the bars $E_{\mathrm{B}}=72389 \mathrm{MPa}$ was determined by ultrasonic methods. Force equilibrium was achieved when $F_{1}(t)=F_{2}(t)$, i.e. $\varepsilon_{\mathrm{I}}(t)+\varepsilon_{\mathrm{R}}(t)=$ $\varepsilon_{\mathrm{T}}(t)$. Hence, the relative displacement of the loading pins was then given by:

$$
\delta(t)=z_{1}(t)-z_{2}(t)=-2 c_{\mathrm{B}} \int_{0}^{t} \varepsilon_{\mathrm{R}}\left(t^{\prime}\right) \mathrm{d} t^{\prime} .
$$

Near-field strain gauges were utilised to detect the point of crack initiation, see Fig. 2. Furthermore, statically calibration of these strain gauges enabled the calculation of the force $\left(F_{\mathrm{SG}}\right)$ and the stress intensity factor $\left(K_{\mathrm{I}, \mathrm{SG}}\right)$.

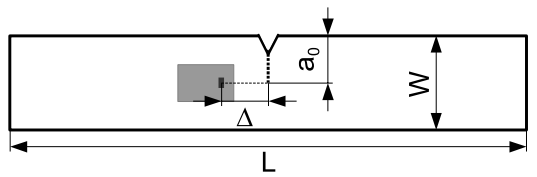

Figure 2. Near-field strain gauge used for the detection of crack initiation. Nominal sample dimensions: $W=10 \mathrm{~mm}$, $a_{0}=5 \mathrm{~mm}, B=10 \mathrm{~mm}, B_{\mathrm{N}}=8 \mathrm{~mm}$ (side-grooved sample), $L=55 \mathrm{~mm}$.

The specimen loading was additionally analysed by means of high-speed photography. The high-speed camera Photron FASTCAM SA-Z enabled high frame rates of $330,000 \mathrm{fps}$ in combination with a image size of $384 \times$ 96 pixels.

\subsection{Calculation of the $\mathrm{J}$ integral}

Under the assumption of quasi-static conditions, the $\mathrm{J}$ integral at the point of crack initiation was determined according to ISO 12135 [14]:

$$
J=\frac{K^{2}\left(1-v^{2}\right)}{E}+\frac{2 U_{\mathrm{p}}}{B_{\mathrm{N}}\left(W-a_{0}\right)} .
$$

The quasi-static stress intensity factor $K_{\mathrm{I}}^{\text {stat }}$ was calculated for the four-point bend loading according to ASTM C 1421 [15]:

$$
K_{\mathrm{I}}^{\text {stat }}=\frac{F\left(S_{\mathrm{o}}-S_{\mathrm{i}}\right)}{B W^{3 / 2}} \cdot \frac{3\left(a_{0} / W\right)^{1 / 2}}{2\left(1-a_{0} / W\right)^{3 / 2}} \cdot f\left(a_{0} / W\right) .
$$

The plastic part of the energy $U_{\mathrm{p}}$ was determined from the force-displacement curve. During force equilibrium, $F_{1}$ and $F_{2}$ can be used to calculate $K_{\mathrm{I}}^{\text {stat }}$ and $U_{\mathrm{p}}$.

Due to possible bending vibrations of the specimen, the dynamic stress intensity factor $K_{\mathrm{I}}^{\mathrm{dyn}}$ was calculated according to Rokach [16-18]. The calculation of $K_{\mathrm{I}}^{\mathrm{dyn}}(t)$ involves both the force in the incident bar and in the transmission bar. An unsupported two-point loading by each bar was assumed. Finally, the stress intensity factor for four-point bending was obtained by superposition of the two separate loads. 

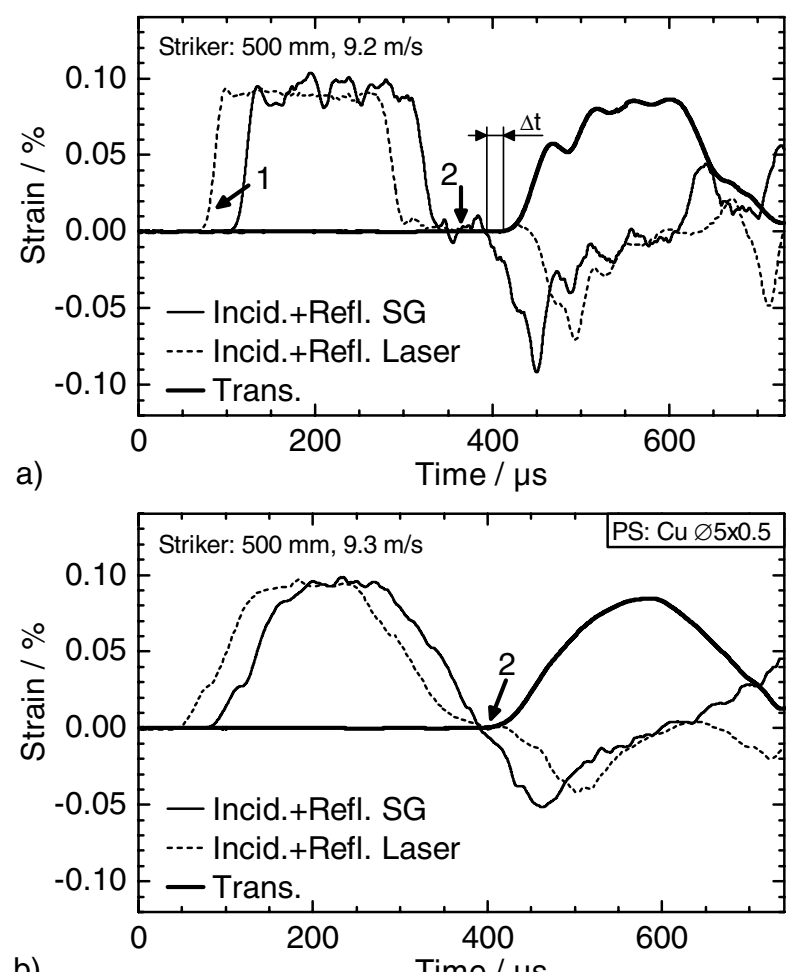

b)

Time / $\mu \mathrm{s}$

Figure 3. Strain history of the incident bar and the transmission bar measured by strain gauges at the mid-length of the bars (unnotched specimen). Additional application of laser measurement. a) unshaped pulse, b) shaped incident pulse.

\subsection{Fractography}

Fracture surface analyses was performed by means of scanning electron microscopy (SEM). The SEM MIRA 3 XMU (TESCAN) enabled beam tilting and, therefore, the determination of height information of the fracture surface [19].

\section{Results}

\subsection{Evaluation of laser measurement}

Figure 3 shows stress pulses obtained from strain gauge and laser measurement. The offset in time (arrow 1) between the two measurements at the incident bar was defined by the distance between the laser measurement site and the position of the strain gauge. Using a pulse shaper and the strain gauge measurement, the end of the incident pulse interfered with the beginning of the reflected pulse (arrow 2). However, the beginning of the reflected pulse is of great importance for the calculation of $F_{1}$ and, therefore, the analysis of the force equilibrium at the early part of loading. The additional measurement site enabled the acquisition of separate pulses $\varepsilon_{\mathrm{I}}$ and $\varepsilon_{\mathrm{R}}$ also in the case of an intensively shaped pulse.

Both strain gauge measurement sites on the incident bar and the transmission bar have a distance of $750 \mathrm{~mm}$ to the loading pins. Hence, the offset in time between the start of the reflected pulse and the transmitted pulse
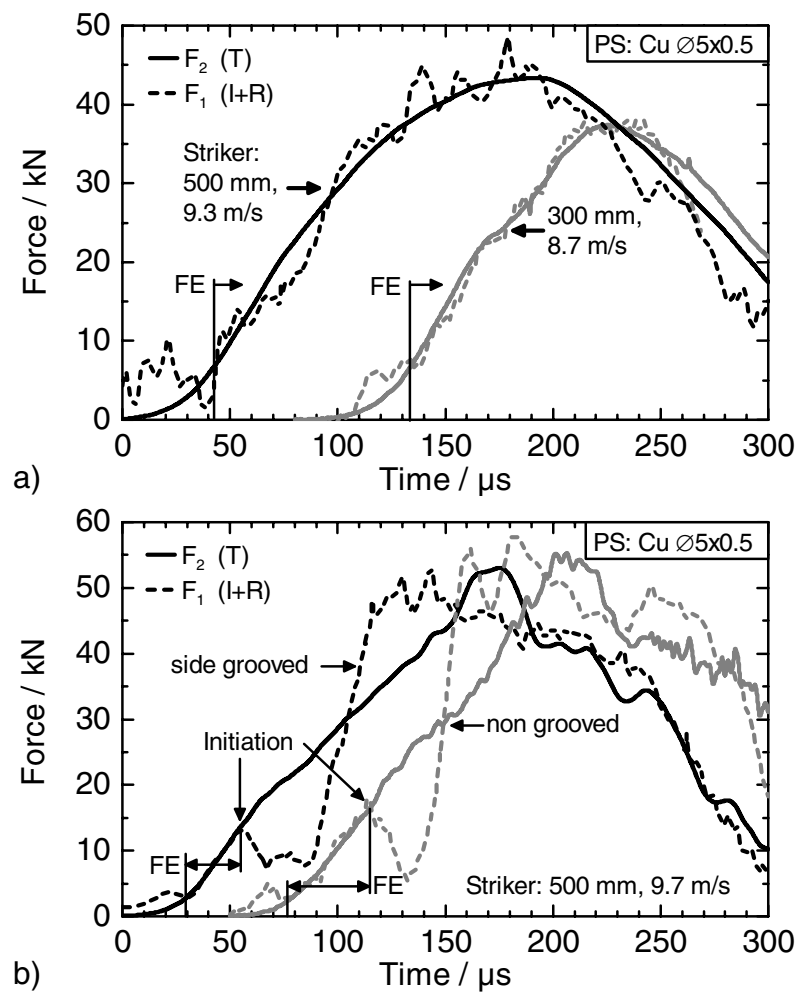

Figure 4. a) Force equilibrium (FE) is achieved after a short time. b) Loss of force equilibrium due to crack initiation. Signals are shifted for better visibility. Material: G42CrMoS4.

was attributed to the time needed for the stress wave to propagate through the sample.

\subsection{Force equlibrium and crack initiation}

The applicability of the shaped incident pulse for achieving an early force equilibrium is shown in Fig. 4. After a short time of approximately $40 \mu \mathrm{s}$, force equilibrium was achieved in the case of unnotched samples (Fig. 4a). The force equilibrium was then maintained throughout the loading of the specimen. Due to a similar incident pulse generated by a different length of the striker $(300 \mathrm{~mm}$ and $500 \mathrm{~mm}$ ), the time to achieve the force equilibrium was independent of the striker length.

In the case of the cracked specimens (Fig. 4b), the force equilibrium was achieved at low forces. After further loading, the force/time history was characterised by a loss of force equilibrium. The force in the incident bar decreased rapidly. This was attributed to the increase in specimen compliance due to crack initiation. In order to compensate the force decrease due to compliance increase, an additional displacement of the incident bar would be necessary. However, the velocity of the incident bar was defined by the magnitude of the incident pulse. Hence, it was assumed that a considerably higher velocity of the incident bar results in the additional displacement needed to achieve further force increase. After the specimen came into contact with the stop block, there was an approximate force equilibrium.

The static calibration of the near-field strain gauge enabled the additional force measurement directly by the 


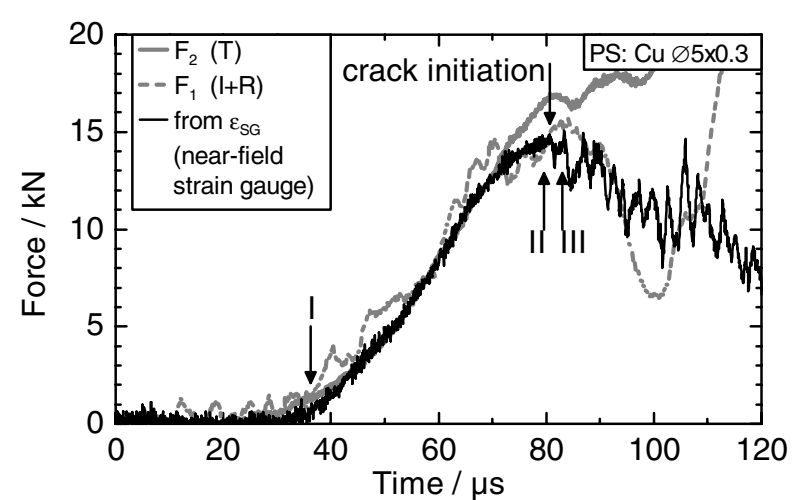

Figure 5. Force measurement by near-field strain gauge $\left(\varepsilon_{S G}\right)$ equivalent to force measurement by the bars (Eqs. (2) and (3)). Material: $42 \mathrm{CrMo} 4$.

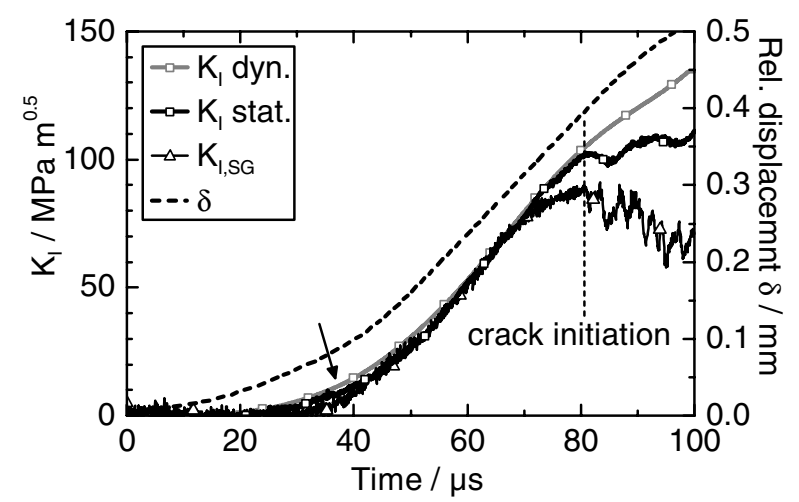

Figure 6. Almost no difference between $K_{\mathrm{I}}^{\text {stat }}$ (calculated with $\left.F_{2}\right)$ and $K_{\mathrm{I}, \mathrm{SG}}\left(K_{\mathrm{I}, \mathrm{SG}} \sim F_{\mathrm{SG}} \sim \varepsilon_{\mathrm{SG}}\right)$ during elastic sample behaviour. Good description of the crack-tip loading by $\mathrm{K}_{\mathrm{I}}^{\mathrm{dyn}}$ as calculated according to Rokach [16-18]. Material: 42CrMo4.

specimen. It was observed that the force measurement by the specimen essentially reflected the force measurement by the bars (Fig. 5). However, the beginning of the loading was characterised by an increase of forces measured by the bars whereas the force obtained from the specimen was approximately zero. This was attributed to the force disequilibrium introduced by stress wave propagation in the specimen. However, several reflections of the stress waves within the specimens were needed in order to load the sample and, therefore, the crack tip.

The calculation of the dynamic stress intensity factor revealed that static as well as dynamic evaluation of the specimen loading led to equal results if force equilibrium was achieved (Fig. 6). After crack initiation, the static and the dynamic calculation resulted in different stress intensity factors due to the force disequilibrium. Furthermore, the unknown crack extension rendered the calculation of $K_{\mathrm{I}}$ impossible.

The signal of the near-field strain gauge was analysed with respect to the point of crack initiation (Fig. 5). At the point of crack initiation, elastic strain energy was released due to the increase in specimen compliance. Hence, the measured strain was significantly reduced. Furthermore, the signal of the near-field strain gauge exhibited oscillations which were explained by reflections

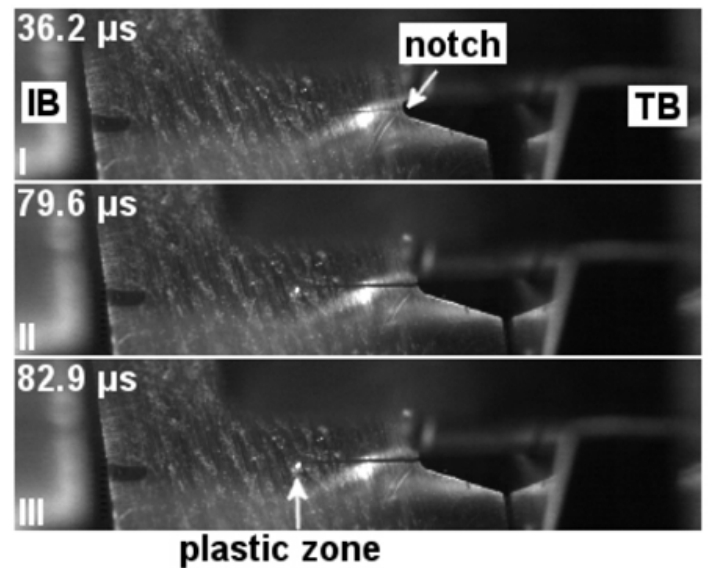

Figure 7. Evolution of plastic zone: I - beginning of loading, II shortly before crack initiation, III - shortly after crack initiation. IB: incident bar, TB: transmission bar.

of the unloading wave within the specimen. One distinctive frequency component of the mixture of oscillations was, e.g. approximately $312 \mathrm{kHz}$. This frequency represents a shear wave which propagates along the length $W$ and is reflected at the front and the back of the specimen.

The point of crack initiation was additionally investigated by means of high-speed photography. Figure 7 shows three frames which were shot at the times I, II and III marked in Fig. 5. It can be seen that the size of the plastic zone at the surface of the sample strongly increased after crack initiation. The crack initiation was not directly visible on the surface of the specimen. This was attributed to the low constraint at the free surface. In contrast, crack initiation was promoted in the centre of the specimen. Hence, the crack opening due to crack initiation in the centre then resulted in the strong increase in plastic zone size at the surface of the specimen.

The J-Integral was calculated at the point of crack initiation. The average crack resistance was $26 \mathrm{~kJ} / \mathrm{m}^{2}$ with a standard deviation of $6 \mathrm{~kJ} / \mathrm{m}^{2}$. The determination of the point of crack initiation was possible with an accuracy of approximately $1 \mu \mathrm{s}$. This time range results in a deviation of typically $4 \mathrm{~kJ} / \mathrm{m}^{2}$. Comparing this first estimation of dynamic crack initiation resistance at loading rates of about $2 \cdot 10^{6} \mathrm{MPa} \sqrt{\mathrm{ms}}{ }^{-1}$ with results of tests performed at smaller loading rates no pronounced embrittlement was observed. Quasi-static tests with $\dot{K}=$ $2 \mathrm{MPa} \sqrt{\mathrm{ms}^{-1}}$ and dynamic tests at $8 \cdot 10^{4} \mathrm{MPa} \sqrt{\mathrm{ms}^{-1}}$ resulted in values of the crack initiation toughness of approximately 45 and $40 \mathrm{~kJ} / \mathrm{m}^{2}$, respectively. According to Klepaczko [10], a minimum of toughness in the range of $10^{3}$ to $10^{5} \mathrm{MPa} \sqrt{\mathrm{ms}}{ }^{-1}$ is observed for the steel $\mathrm{C} 45$. Hence, further investigations are necessary to characterise a possible minimum for the present steel.

\subsection{Fractography}

A fracture surface of the material is shown in Fig. 8. It was observed that the blunting of the precrack depended strongly on the local microstructure, i.e. the local inclusion distribution, in front of the crack tip. Regions which were characterised by an agglomeration of non-metallic 


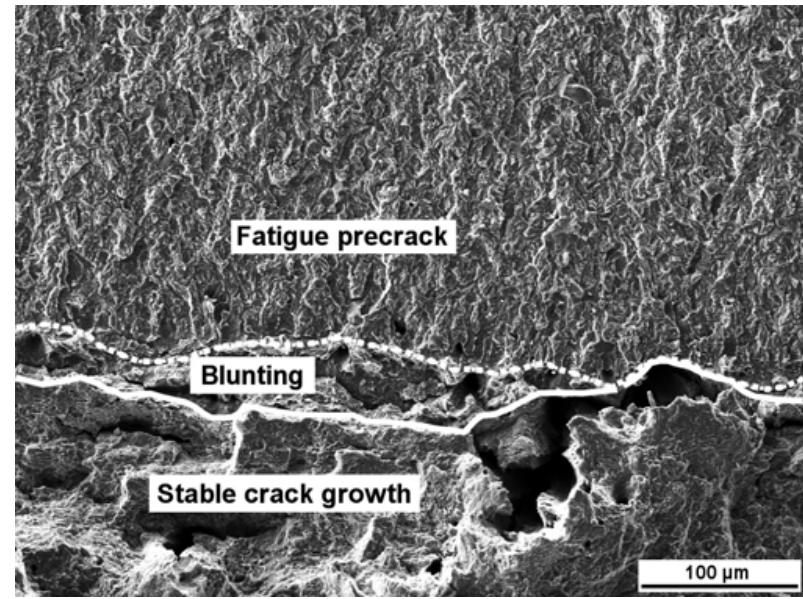

Figure 8. Crack initiation was strongly affected by the local distribution of non-metallic inclusions. Material: G42CrMoS4.

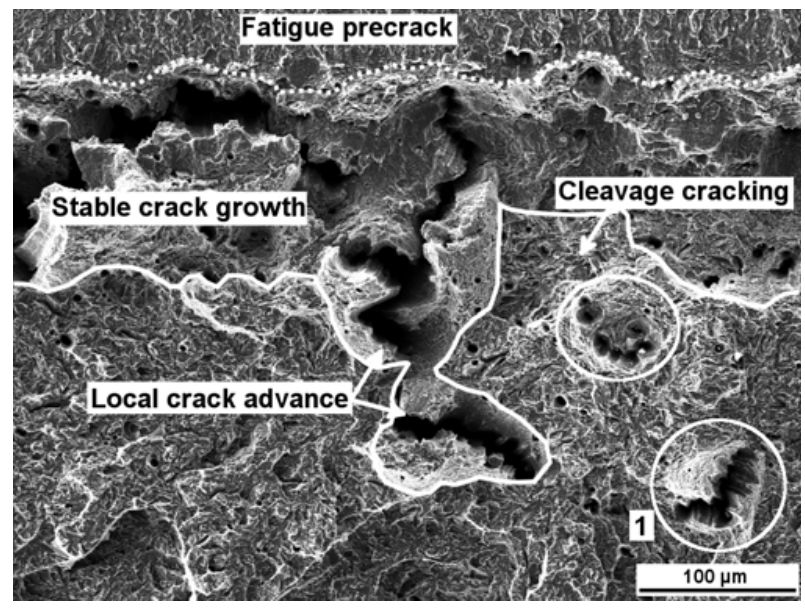

Figure 9. Local crack growth due to chains of non-metallic inclusions. Material: G42CrMoS4.

inclusions exhibited no crack tip blunting. Hence, the crack initiation resistance was not uniquely defined.

As shown in Fig. 9, local crack growth was another effect of the inhomogeneous distribution of the nonmetallic inclusions. Chains of non-metallic inclusions resulted in locally enhanced crack growth rates. As a consequence, crack tip shielding decreased the crack driving force which eventually stopped the crack growth. Furthermore, ductile voids were observed which were surrounded by cleavage facets (label 1 in Fig. 9). The cleavage facets were attributed to the final cracking at low temperatures. However, the ductile voids were formed during the actual test which was confirmed by the oxidised surface due to heat tinting. Hence, there was a connection between the apparently separate ductile fracture surfaces. This connection was explained by secondary cracks.

The direction of the elongated $\mathrm{MnS}$ inclusion was mainly perpendicular to the plane of the fracture surface. As a result, crack path deflection occurred. However, this principally toughness-increasing mechanism was not considered to be effective due to the promotion of void initiation, growth and coalescence by the MnS inclusions.

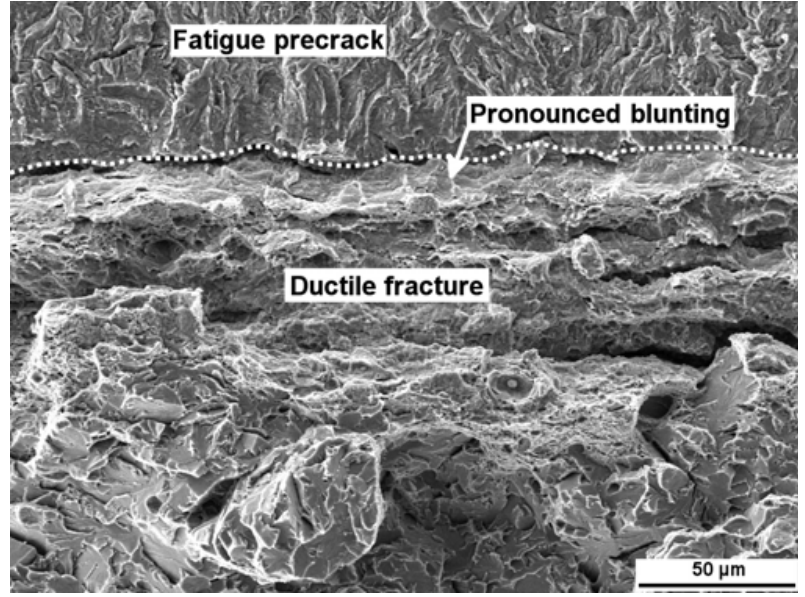

Figure 10. Blunting of precrack before crack initiation. Material: $42 \mathrm{CrMo} 4$.

In Fig. 10, the fracture surface of the $42 \mathrm{CrMo} 4$ steel used for comparison is shown. The fracture surface exhibited blunting of the precrack due to the relatively low inclusion content of this steel. Furthermore, crack path deflection was less distinctive than in the steel with the elongated $\mathrm{MnS}$ inclusions. No regions with local crack advance were observed.

\section{Conclusions}

In this paper, the resistance against crack initiation in a high-strength G42CrMoS4 cast steel was evaluated at very high loading rates of $2 \cdot 10^{6} \mathrm{MPa} \sqrt{\mathrm{m}} / \mathrm{s}$. The tests were performed by the application of a specially designed fourpoint bending split Hopkinson pressure bar. The main conclusions can be drawn as follows:

- The steel G42CrMoS4 exhibited crack-tip blunting (locally) followed by stable crack growth. Stable crack growth was achieved by ductile fracture. Crack path deflection was locally observed and was caused by elongated manganese sulphide inclusions.

- A significant embrittlement effect due to the elongated $\mathrm{MnS}$ inclusions was observed. Crack path deflection as a possible toughness-increasing mechanism was considered to be ineffective due to the damaging effect of the non-metallic inclusions.

- Due to irregularly developed crack-tip blunting, crack initiation was considered not to be a single step. Regions that exhibited non-metallic inclusions at the tip of the fatigue precrack showed no blunting. However, areas which were essentially characterised by the deformation of the metallic matrix did show blunting of the crack tip.

- The statistical distribution of the non-metallic inclusions along the crack front led to a scattering of the resistance against crack initiation. A slight decrease of toughness compared to $J_{\mathrm{i}}$ determined at smaller loading rates was observed. Further investigations of the loading rate dependence of the crack initiation toughness are necessary. 
- When dynamic force equilibrium was achieved, the description of sample loading by the static and the dynamic stress intensity factors led to similar results.

The authors thank the German Research Foundation (DFG) for its financial support of the investigations at the Collaborative Research Center 920, subproject C05. The support of Markus Radajewski during the experimental work and the help of Thomas Meier (VKT Video Kommunikation $\mathrm{GmbH}$ ) with the high-speed camera are greatly appreciated.

\section{References}

[1] K. Tanaka, T. Kagatsume, Bull. JSME 23, 1736 (1980)

[2] L. Rubio, J. Fernández-Sáez, C. Navarro, Exp. Mech. 43, 379 (2003)

[3] T. Weerasooriya, P. Moy, D. Casem, M. Cheng, W.W. Chen, J. Am. Ceram. Soc. 89, 990 (2006)

[4] F. Jiang, K.S. Vecchio, Metall. Mater. Trans. A 38, 2896 (2007)

[5] J.T. Foster, W.W. Chen, V.K. Luk, Eng. Fract. Mech. 78, 1264 (2011)

[6] Z. Xu, Y. Li, Acta Mech. Sin. 27, 559 (2011)

[7] S.F. Zhu, C. Yang, C.H. Guo, F. Jiang, Key Eng. Mat. 577-578, 517 (2014)
[8] T. Demler, Ph.D. thesis, Universität Stuttgart (1990)

[9] J.F. Kalthoff, S. Winkler, W. Böhme, J. Phys. Colloques 46, 179 (1985)

[10] J.R. Klepaczko, J. Eng. Mater. Techn. 104, 29 (1982)

[11] J.R. Klepaczko, Int. J. Impact Eng. 3, 191 (1985)

[12] S. Henschel, L. Krüger, K. Mandel, M. Radajewski, Studie zur Impulsformung an Split-HopkinsonAufbauten, in 15. Werkstofftechnisches Kolloquium, edited by B. Wielage (2012), pp. 422-427

[13] G.T. Gray, in ASM-Handbook, edited by H. Kuhn, D. Medlin (ASM, Ohio, 2000), Vol. 8, pp. 462-476

[14] ISO 12135:2002 (2002), Metallic materials - Unified method of test for the determination of quasistatic fracture toughness

[15] ASTM C 1421-10 (2010), Standard test methods for determination of fracture toughness of advanced ceramics at ambient temperature

[16] I.V. Rokach, Fatigue Fract. Engng. Mater. Struct. 21, 1007 (1998)

[17] I.V. Rokach, Fatigue Fract. Engng. Mater. Struct. 21, 1015 (1998)

[18] I.V. Rokach, P. Łabȩdzki, Int. J. Fracture 160, 93 (2009)

[19] A. Weidner, T. Mottitschka, H. Biermann, S. Henkel, Eng. Fract. Mech. 108, 294 (2013) 